\title{
Herpesvirus: relación con la enfermedad periodontal e implicaciones orales
}

\author{
Cristian Gabriel Guerrero Bernal, ${ }^{*}$ Claudia Tinoco Cabral, ${ }^{\ddagger}$ \\ Jesús Morales Martínez, ${ }^{\S}$ Alejandro Gutiérrez Guerra," Lucila Hernández Andrade," \\ Jorge Gaona Bernal," Iván Isidro Hernández Cañaveral**
}

\section{RESUMEN}

La periodontitis es una enfermedad crónica inflamatoria que produce una destrucción de las estructuras de soporte del diente, provocando su pérdida. Los agentes bacterianos organizados en forma de biofilm son clave en el desarrollo de la periodontitis pero su presencia por sí sola no siempre puede explicar las características clínico-patológicas de la enfermedad. La evidencia sugiere que los herpesvirus y las bacterias podrían cooperar de forma sinérgica en el desarrollo de la periodontitis, respaldando una asociación, ya que una infección por herpesvirus activo puede inducir la inmunosupresión, llevando a un sobrecrecimiento de bacterias patógenas, y potencialmente convertir la gingivitis en periodontitis o la periodontitis estable en enfermedad progresiva. Algunos estudios indicaron un riesgo significativamente mayor de periodontitis acompañada por una mayor prevalencia de detección de herpesvirus. Millones de copias genómicas de virus humanos se pueden alojar en lesiones periodontales, y los herpesvirus son los virus más investigados en periodontología. Los pacientes con periodontitis presentan niveles séricos elevados de anticuerpos contra el herpesvirus y mediadores inflamatorios.

Palabras clave: Herpesvirus, enfermedad periodontal, periodontitis, virus, herpes labial, inflamación gingival.

\section{INTRODUCCIÓN}

El término herpes proviene de la palabra griega "Herpein" que significa serpentar, que hace refe-

\footnotetext{
* Licenciatura Médico Cirujano Dentista.

‡ Maestría en Educación, Técnico Académico asistente de tiempo completo del Postgrado de Periodoncia.

$\S$ Licenciatura en Enfermería.

॥ Químico Farmacobiólogo.

? Doctorado en Ciencias.

** Doctorado en Ciencias y Biología Molecular.
}

Departamento de Microbiología y Patología, Centro Universitario de Ciencias de la Salud, Universidad de Guadalajara.

Recibido: 03 de octubre de 2019. Aceptado: 04 de diciembre de 2019.

Este artículo puede ser consultado en versión completa en www.medigraphic.com/periodontologia

\begin{abstract}
Periodontitis is a chronic inflammatory disease that causes destruction of the support structures of the tooth, causing its loss. Bacterial agents organized in the form of biofilm are key in the development of Periodontitis but their presence alone cannot always explain the clinical-pathological characteristics of the disease. The evidence suggests that herpesviruses and bacteria could cooperate synergistically in the development of periodontitis, supporting an association, since an active herpesvirus infection can induce immunosuppression leading to an overgrowth of pathogenic bacteria, and potentially convert gingivitis into periodontitis or stable periodontitis in progressive disease. Some studies indicated a significantly higher risk of periodontitis accompanied by a higher prevalence of herpesvirus detection. Millions of genomic copies of human viruses can be housed in periodontal lesions, and herpesviruses are the most researched viruses in periodontology. Patients with periodontitis have elevated serum levels of antibodies against Herpesvirus and inflammatory mediators.
\end{abstract}

Keywords: Herpesvirus, periodontal disease, periodontitis, virus, oral herpes, gingival inflammation.

rencia a su capacidad de permanecer en forma latente después de la primo infección y reactivarse ante un estímulo. ${ }^{1}$

Los herpesvirus son miembros de la familia Herpesviridae. Se han identificado más de 100 tipos diferentes de Herpesvirus pertenecientes a la familia Herpesviridae, de los cuales sólo ocho tipos son capaces de infectar a humanos y se agrupan en tres subfamilias: Alfa, Beta y Gammaherpesvirinae (Tabla 1). ${ }^{2}$

\section{Fenotipo viral}

Están formados por una cápside icosaédrica de 162 capsómeros, y un diámetro de 120 a 200 nanómetros, dependiendo del grosor del tegumento. El tegumento es una estructura proteínica que envuelve la cápside. Los herpesvirus envueltos 
Rev Mex Periodontol 2019; X (3): 58-64

\section{Tabla 1: Principales características de los herpesvirus de la familia Herpesviridae.}

\begin{tabular}{|c|c|c|c|c|c|}
\hline Virus & Subfamilia & Sitios de latencia & $\begin{array}{l}\text { Vías de transmisión } \\
\text { y formas de contagio }\end{array}$ & Infección primaria & $\begin{array}{l}\text { Infección } \\
\text { recurrente }\end{array}$ \\
\hline $\begin{array}{l}\text { Herpes simple tipo } \\
1 \text { (HSV-1) }\end{array}$ & Alphaherpesvirinae & $\begin{array}{l}\text { Ganglios sensitivos } \\
\text { (neuronas) }\end{array}$ & $\begin{array}{l}\text { Transmisión oral } \\
\text { (saliva, contacto } \\
\text { directo, secreciones } \\
\text { respiratorias) }\end{array}$ & $\begin{array}{l}\text { Gingivoestomatitis } \\
\text { herpética primaria }\end{array}$ & $\begin{array}{l}\text { Herpes labial, } \\
\text { queratitis, } \\
\text { encefalitis }\end{array}$ \\
\hline $\begin{array}{l}\text { Herpes simple tipo } \\
2 \text { (HSV-2) }\end{array}$ & Alphaherpesvirinae & $\begin{array}{l}\text { Ganglios sensitivos } \\
\text { (neuronas) }\end{array}$ & $\begin{array}{l}\text { Transmisión sexual, } \\
\text { perinatal }\end{array}$ & Herpes genital & $\begin{array}{l}\text { Herpes genital, } \\
\text { meningitis }\end{array}$ \\
\hline $\begin{array}{l}\text { Herpes } \\
\text { varicela-zóster } \\
(\mathrm{HHV}-3)\end{array}$ & Alphaherpesvirinae & $\begin{array}{l}\text { Ganglios sensitivos } \\
\text { (neuronas) }\end{array}$ & $\begin{array}{l}\text { Transmisión oral } \\
\text { (saliva, contacto } \\
\text { directo, secreciones } \\
\text { respiratorias) }\end{array}$ & Varicela & Herpes zóster \\
\hline $\begin{array}{l}\text { Virus de } \\
\text { Epstein-Barr } \\
\text { (HHV-4) }\end{array}$ & Gammaherpesvirinae & Linfocitos B & $\begin{array}{l}\text { Transmisión oral, } \\
\text { faríngea, sanguínea }\end{array}$ & $\begin{array}{l}\text { Mononucleosis } \\
\text { infecciosa }\end{array}$ & $\begin{array}{l}\text { Afecciones } \\
\text { sistémicas, } \\
\text { diversas } \\
\text { neoplasias }\end{array}$ \\
\hline $\begin{array}{l}\text { Citomegalovirus } \\
\text { (HHV-5) }\end{array}$ & Betaherpesvirinae & $\begin{array}{l}\text { Glándulas } \\
\text { secretoras, células } \\
\text { linfoides, monocitos }\end{array}$ & $\begin{array}{l}\text { Transmisión } \\
\text { perinatal, faríngea, } \\
\text { genital, sanguínea } \\
\text { y donación de } \\
\text { órganos }\end{array}$ & $\begin{array}{l}\text { Mononucleosis, } \\
\text { infección congénita }\end{array}$ & $\begin{array}{l}\text { En pacientes } \\
\text { inmunodeprimidos: } \\
\text { retinitis, neumonía, } \\
\text { encefalitis }\end{array}$ \\
\hline $\begin{array}{l}\text { Herpes tipo } 6 \\
(\mathrm{HHV}-6)\end{array}$ & Betaherpesvirinae & $\begin{array}{l}\text { Linfocitos T, } \\
\text { monocitos y } \\
\text { macrófagos }\end{array}$ & $\begin{array}{l}\text { Transmisión oral, } \\
\text { faríngea mediante } \\
\text { saliva }\end{array}$ & $\begin{array}{l}\text { Exantema súbito } \\
\text { (roséola) }\end{array}$ & $\begin{array}{l}\text { En pacientes } \\
\text { inmunodeprimidos: } \\
\text { encefalitis, } \\
\text { diseminación } \\
\text { sistémica }\end{array}$ \\
\hline $\begin{array}{l}\text { Herpes tipo } 7 \\
\text { (HHV-7) }\end{array}$ & Betaherpesvirinae & Linfocitos T (CD4) & $\begin{array}{l}\text { Transmisión oral, } \\
\text { faríngea mediante } \\
\text { saliva }\end{array}$ & Fiebre, leucopenia & Indeterminada \\
\hline $\begin{array}{l}\text { Herpes asociado } \\
\text { al Sarcoma de } \\
\text { Kaposi (HHV-8) }\end{array}$ & Gammaherpesvirinae & Linfocitos B & $\begin{array}{l}\text { Transmisión sexual } \\
\text { o por donación de } \\
\text { órganos }\end{array}$ & $\begin{array}{l}\text { Virus relacionados } \\
\text { con sarcoma de } \\
\text { Kaposi }\end{array}$ & $\begin{array}{l}\text { Sarcoma de } \\
\text { Kaposi }\end{array}$ \\
\hline
\end{tabular}

contienen glicoproteínas que les ayudan al virus a entrar en la célula. ${ }^{3}$

\section{Genotipo viral}

Contienen un núcleo central de ácido desoxirribonucleico (ADN), lineal en doble cadena y está en forma de resorte incrustado en un huso proteínico.

El ADN viral de los herpesvirus codifica proteínas que participan en el establecimiento, latencia, producción de $\mathrm{ADN}$ viral y proteínas estructurales para la formación de la cápside, así como proteínas encargadas del bloqueo y la modificación del sistema inmune, y también interviene en las modificaciones del estado de latencia o lisis celular. ${ }^{3}$

\section{Periodontitis}

Es una enfermedad compleja que se encuentra entre las enfermedades inflamatorias crónicas más prevalentes en todo el mundo. Se considera que la periodontitis implica una interacción multifactorial entre el hospedero, los patógenos periodontales y el medio ambiental, que conducen 
a una alteración de la homeostasis y destrucción del tejido periodontal. ${ }^{4}$

Los agentes bacterianos organizados en forma de biofilm son de importancia clave en el desarrollo de la periodontitis. Aunque la presencia de bacterias Gram negativas específicas es esencial para el inicio de la enfermedad periodontal, su presencia por sí sola no siempre puede explicar las características clínico-patológicas presentadas en la enfermedad. ${ }^{5}$

Slot presentó evidencia de que los virus y las bacterias en conjunto producen un efecto patógeno mayor y el modelo actual de la patogénesis de la periodontitis debe revisarse de acuerdo con el concepto de coinfección herpesviral-bacteriana. Los herpesvirus pueden reducir la capacidad de los tejidos periodontales para resistir la invasión bacteriana mediante la infección o alteración de células estructurales o células de defensa del huésped del periodonto. ${ }^{6}$

\section{Epidemiología}

La mayoría de los casos de periodontitis comienzan en la tercera década de la vida, llegando a su máxima expresión entre los 45-50 años, pero pueden comenzar a cualquier edad. Cuatro mil millones de personas en todo el mundo tienen antecedentes de periodontitis, y se estima que la prevalencia global de periodontitis severa es de $11 \%$. La periodontitis también se ha asociado con al menos 57 enfermedades. La asociación entre la periodontitis y la morbilidad sistémica puede ser el resultado de que los herpesvirus periodontales ingresen a la circulación sistémica e infecten sitios distantes del cuerpo. ${ }^{2}$

Los herpesvirus son los virus más comunes en los seres humanos, que infectan $80-90 \%$ de la población adulta mundial y la primoinfección (gingivoestomatitis herpética) generalmente ocurre durante la infancia. ${ }^{6}$

\section{ETIOPATOGENIA}

La especificidad de los herpesvirus radica principalmente en sus receptores glicoprotéicos que se encuentran en su envoltura. El virus inicia la infección en las membranas de las mucosas, se replica en las células mucoepiteliales originando infección lítica y se disemina a las células adyacentes y neuronas que inervan el sitio donde se inició la infección aguda. ${ }^{2}$

La infección latente en la neurona no produce daño aparente, pero diferentes estímulos la pueden reactivar: inmunosupresión, infección, estrés emocional prolongado, cambios hormonales, trauma, cambios de temperatura, etcétera. ${ }^{7}$

Una infección por herpes en el periodonto puede alterar la inmunidad local y dar lugar a un crecimiento de patógenos bacterianos y, posteriormente, a la enfermedad periodontal destructiva. ${ }^{8}$

Autores como Slots y Contreras han intentado esclarecer la posible asociación entre los herpesvirus y la periodontitis, y han descrito cinco mecanismos que pueden explicar el carácter periodontopatógeno de los herpesvirus:

- Capacidad de causar daños citopáticos en fibroblastos, queratinocitos, células endoteliales e inflamatorias.

- Capacidad de actuar negativamente sobre las células de defensa del huésped, predisponiendo al sujeto a una sobreinfección bacteriana.

- La infección gingival por herpesvirus puede facilitar la colonización subgingival por bacterias periodontopatógenas.

- Las infecciones virales podrían alterar la respuesta inflamatoria, aumentando la producción de mediadores proinflamatorios.

- Daño directo sobre los tejidos como consecuencia de la respuesta inmunopatológica a las células infectadas por el virus. ${ }^{9}$

Los virus del herpes se dirigen a varias células del sistema inmune y alteran sus funciones para su propio beneficio. Se sabe que el citomegalovirus infecta a monocitos/macrófagos periodontales y linfocitos $\mathrm{T}$, que EBV infecta a linfocitos B periodontales. Estas células infectadas estimulan la producción de citocinas, activando mecanismos involucrados en la destrucción periodontal como inflamación, degradación del colágeno y resorción ósea. ${ }^{7}$

La liberación prolongada o la sobreproducción de citocinas proinflamatorias activa a los osteoclastos y metaloproteinasas de matriz (colagenasas). ${ }^{10}$

Los virus codifican las glucoproteínas inmunoevasivas que interfieren con la presentación del antígeno, la vigilancia inmunitaria de las células $\mathrm{T}$ y la función de las células asesinas naturales. Las proteínas virales buscan alterar o imitar la función de las principales proteínas del complejo de histocompatibilidad, activación y migración de leucocitos, inducción y actividad de citocinas e interferones, mecanismos de defensa basados en anticuerpos y 
susceptibilidad de las células huésped a la apoptosis. La incidencia y gravedad de la enfermedad por herpesvirus es elevada en pacientes inmunológicamente inmaduros y en personas inmunodeprimidas (infección por VIH/SIDA, quimioterapia, radioterapia, inmunosupresión farmacológica por trasplante de órganos, etcétera). ${ }^{2}$

\section{Manifestaciones ClíNICAS DE HERPESVIRUS}

\section{Familia Alphaherpesvirinae}

Virus herpes simple tipo 1 (HSV-1)

En una infección primaria por HSV-1 que se adquiere por contacto con el virus presente en lesiones o secreciones de individuos enfermos o portadores asintomáticos. Infecta principalmente tejido epitelial y mucosa facial, su manifestación clínica primaria es la gingivoestomatitis herpética. Estas lesiones generalmente se presentan en niños, en forma de erupción vesiculosa en la encía insertada, que puede causar linfadenopatía y fiebre. Después de la infección primaria, las nucleocápsides víricas se transportan a lo largo de los axones hasta los cuerpos neuronales para llegar al ganglio nervioso del trigémino donde permanece de manera latente. La reactivación del HSV-1 puede ocurrir repetidamente

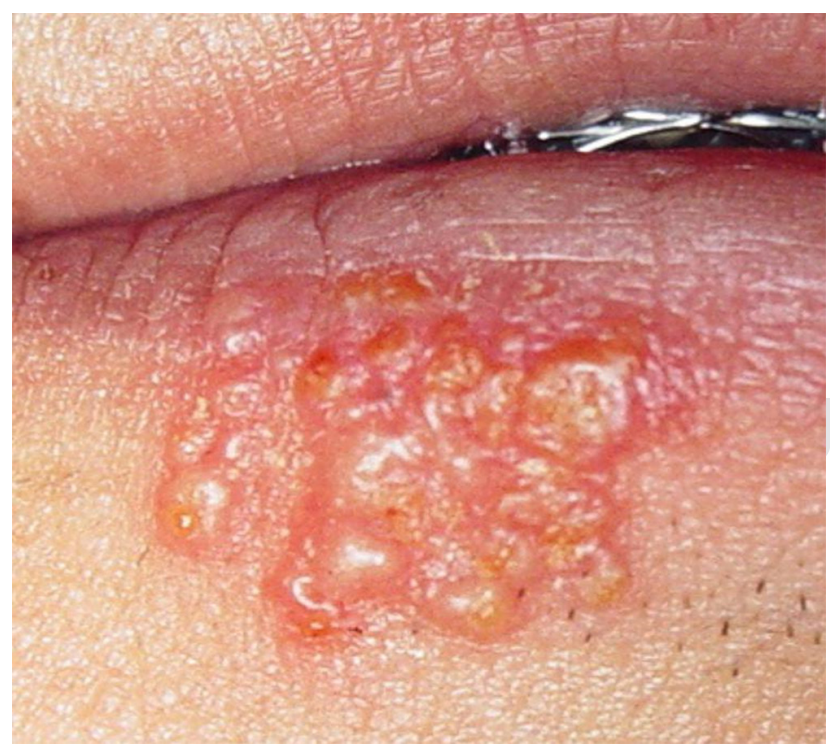

Figura 1: Herpes labial recurrente.

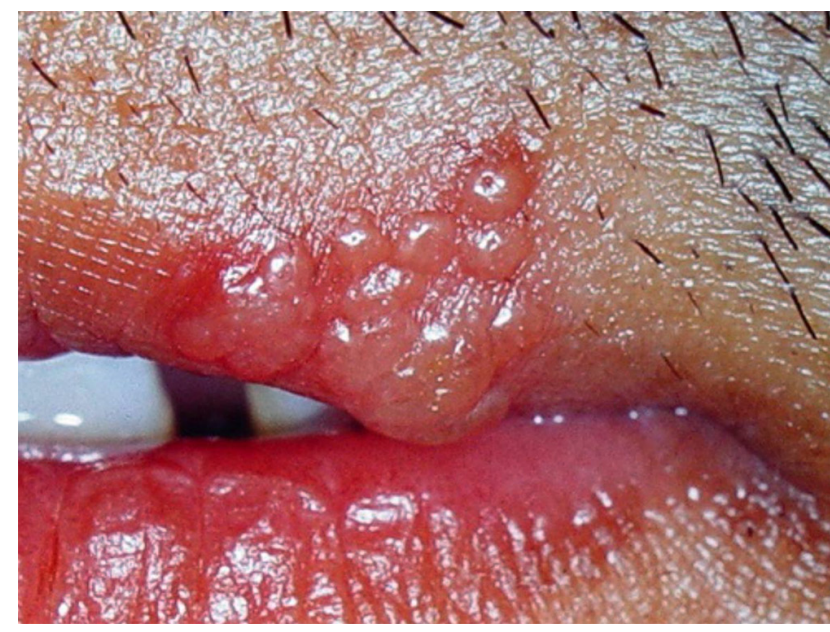

Figura 2: Lesiones en forma de vesícula que al romperse se ulceran.

con o sin síntomas y da lugar a la diseminación del virus desde las neuronas hasta la piel o membranas mucosas. La lesión más representativa de este virus es el herpes labial recurrente (Figura 1), en forma de vesículas que se rompen y provocan úlceras en los labios y el borde bermellón (Figura 2). ${ }^{11}$

Virus herpes simple tipo 2 (HSV-2)

Los HSV-2 entran a las células de la piel y las membranas mucosas por contacto sexual directo de las secreciones o superficies mucosas de la persona infectada, el virus se multiplica en la capa epitelial y después asciende al nervio sensorial y llega al ganglio dorsal donde permanece latente. Frente a ciertos estímulos, el HSV-2 se reactiva, vuelve por los axones hasta el sitio inicial de infección y se excreta en la secreción vaginal o el semen, lo que a veces se acompaña de manifestaciones clínicas. Tras un periodo de incubación de 2-20 días, se observan vesículas agrupadas o erosiones dolorosas sobre una base eritematosa, que se ulceran y luego cicatrizan lentamente. La primoinfección se presenta como una vulvovaginitis o balanitis, con múltiples lesiones que se pueden acompañar de fiebre, adenopatías inguinales y cefalea. Las manifestaciones clínicas y la excreción viral duran dos a tres semanas. En las recurrencias, hay menos lesiones, más localizadas y desaparecen en siete a 10 días. $\mathrm{Al}$ igual que el HSV1 , la primoinfección y la recurrencia son infecciones localizadas. ${ }^{12}$ 
Virus varicella-zóster (VZV, HHV-3)

El VZV es responsable de dos grandes infecciones clínicas: la primera es de tipo Varicela, y la segunda (reactivación del virus) se refiere a Herpes zóster (tipo culebrilla). Las lesiones en la piel de la Varicela se caracterizan por lesiones vesiculares y maculopapulares que son intensamente pruriginosas. Después de la infección primaria (tipo Varicela) por VZV, el virus queda de manera latente en la raíz dorsal o craneal de los ganglios de los nervios, pudiéndose reactivar en 0.3 a $0.5 \%$ de los casos, causando Herpes Zóster (HZ).

Los primeros síntomas de HZ son dolor, sensibilidad y parestesia a lo largo del curso del nervio afectado, posteriormente, vesículas unilaterales que aparecen de tres a cinco días más tarde sobre una base inflamada. Cuando el ganglio geniculado del nervio facial está infectado, los signos característicos incluyen vesículas unilaterales de oído externo y mucosa oral así como parálisis facial. ${ }^{13}$

\section{Familia Betaherpesvirinae}

\section{Citomegalovirus (CMV, HHV-5)}

El virus se transmite por contacto de secreciones orofaríngeas, orina, secreciones vaginales, semen, leche materna, lágrimas, heces y sangre. La infección por este virus es sistémica, se multiplica prácticamente en todos los órganos y se excreta en todas las secreciones corporales. El daño celular es por acción directa de la replicación viral y de la respuesta inmune, generando células gigantes (por eso su nombre), redondeamiento celular e inclusiones intranucleares. El CMV permanece latente en células renales, en células de las glándulas salivales y en polimorfonucleares de sangre periférica. Los síntomas incluyen fiebre, mialgias, adenopatías cervicales y hepatitis leve. Las complicaciones de la infección primaria por CMV pueden incluir miocarditis, neumonitis y meningitis aséptica. ${ }^{14,15}$

\section{HHV-6 y HHV-7}

El virus HHV-6 es un virus ampliamente distribuido en la población mundial y se adquiere a temprana edad por el contacto con saliva infectada. Es linfotrópico (infecta LTCD4), pero se ha detectado en múltiples tejidos y secreciones del organismo, incluyendo la sangre. Puede haber transmisión intrauterina.
El HHV-7 se ha relacionado con numerosas patologías como el exantema súbito, la mononucleosis infecciosa y el síndrome de fatiga crónica, pero su relación oral no está clara. Siendo su principal sitio de replicación la glándula salival, generalmente se transmite por la saliva. Existe interferencia recíproca con el VIH ya que ambos virus utilizan el receptor CD4 para infectar LT.

Se ha detectado en individuos sanos en altos niveles en pulmón, piel y glándula mamaria, y en baja cantidad en hígado, riñón y amígdalas. Esto indicaría que, además de establecer latencia en células mononucleares de sangre periférica, el virus permanecería en forma persistente en tejidos. Ambos virus, el HHV-6 y HHV-7 son patógenos emergentes en poblaciones inmunocomprometidas. ${ }^{9}$

\section{Familia Gammaherpesvirinae}

Virus de Epstein-Barr (EBV, HHV-4)

Se adquiere desde temprana edad y está ampliamente distribuido en la población mundial de países en desarrollo y durante la adolescencia en países desarrollados. La incidencia varía según las áreas geográficas consideradas. En el manto de este virus se encuentra una glicoproteína única, contra la cual se dirige gran parte de la respuesta inmune. Se han identificado dos tipos, EBV-1 y EBV-2, con gran homología genética, observándose con mayor frecuencia el EBV-1 en el continente europeo y americano. El virus de Epstein-Barr (EBV) es causante de la mononucleosis infecciosa (MNI) y también se asocia a cuadros poco frecuentes como linfoma de Burkitt, carcinoma nasofaríngeo y leucoplasia vellosa. ${ }^{9}$

El EBV ingresa vía orofaringe e infecta a las células epiteliales y las glándulas salivales, y se replican en estas células, posteriormente infecta las células $\mathrm{B}$ al entrar en contacto con estas células. Los virus presentan una proteína en su envoltura denominada gp 350, ésta se une al receptor celular CD21, el virus infecta toda célula que tenga este receptor. ${ }^{16}$

Virus asociado a sarcoma de Kaposi (HHV-8)

El herpesvirus humano 8 (HHV-8) fue denominado inicialmente como virus herpes asociado a sarcoma de Kaposi (KSHV), debido a que, en 1994, se detectó originalmente en pacientes con SIDA que presentaban esta patología. Posteriormente, se ha detectado 
en todos los subtipos clínico-epidemiológicos de la enfermedad, sarcoma de Kaposi clásico y endémico. También se ha asociado a carcinomas de células escamosas y básales en pacientes trasplantados con tratamiento inmunosupresor, pero no está confirmada su participación. Este virus infecta a células endoteliales, linfocitos $\mathrm{T}$ y, principalmente, linfocitos B. En las lesiones del sarcoma de Kaposi se observa proliferación de células endoteliales, angiogénesis que estaría inducida por citocinas y factores de crecimiento. Otros factores participarían en el desarrollo de este sarcoma como la coinfección por el VIH, el cual in vitro estimula la replicación del HHV-8. Al parecer, este virus no se encuentra ampliamente diseminado en la población general, habiéndose detectado en $34 \%$ de pacientes con SIDA. ${ }^{17}$

\section{Diagnóstico}

Técnicas basadas en PCR de alta fidelidad se han convertido en el estándar de oro para la identificación y cuantificación de herpesvirus en sitios periodontales. Mediante PCR la identificación de los virus del herpes simple oral puede producir de dos a cuatro muestras más positivas que el cultivo viral. Por otra parte, puede revelar más sitios periodontales que son positivos para herpesvirus que el cultivo viral. Tecnología de PCR anidada es particularmente lo más eficaz en la detección de baja carga viral. Sin embargo, los cebadores de PCR que amplifican las plantillas de las comunidades microbianas en diferentes ciencias pueden dar resultados sesgados. Algo a considerar es que los resultados con herpesvirus pueden ser falsos positivos, y éstos pueden surgir cuando hay regiones de secuencias de nucleótidos compartidos entre especies de herpesvirus y agentes infecciosos desconocidos. Sin embargo, los virus de Epstein-Barr y el citomegalovirus han sido identificados usando una variedad de cebadores de PCR, a través de sus diferentes tipos. ${ }^{18,19}$

Las diferencias geográficas/étnicas juegan un papel importante en la incidencia de los herpesvirus entre las poblaciones. ${ }^{20}$

\section{EXÁMENES COMPLEMENTARIOS}

\section{Cultivo viral}

Esta técnica es insensible para la detección de HSV de úlceras genitales pero es específica para diferenciar HSV-1 y HSV-2, y son más productivas si la muestra se toma en el periodo vesicular y en fase temprana del periodo ulcerativo.

\section{Serología}

Los anticuerpos contra HSV se forman durante las primeras semanas de infección y permanecen de manera indefinida. De 50 a $90 \%$ de los adultos infectados con HSV tienen anticuerpos contra éste, pero sólo $30 \%$ tiene anticuerpos contra HSV-2. Se puede usar como confirmatorio en pacientes que no tienen manifestaciones clínicas y también es útil en cultivo con falsos negativos. En el caso de HSV-2 la prueba de anticuerpos es confirmativa en caso de lesiones en la región ano-genital.

Para el mejor diagnóstico de mononucleosis por CMV, se recomienda la búsqueda de anticuerpos IgM contra CMV ya que a diferencia de otras infecciones virales, las IgM llegan a su pico en infecciones agudas por CMV, y se mantienen elevadas por un año.

Para el caso del virus de Epstein-Barr se recomienda la técnica de Paul-Bunnell. Esta técnica es relativamente insensible en las primeras semanas de la infección y los falsos negativos son altos $(25 \%$ en la primera semana, de 5 a $10 \%$ en la segunda semana y $5 \%$ en la tercera semana). ${ }^{19,21}$

\section{TrATAMIENTO}

El tratamiento farmacológico para los herpevirus son los análogos de nucleótidos como el aciclovir, famciclovir y valaciclovir. Estos tratamientos ofrecen beneficios clínicos pero no curan la enfermedad. Para HSV-1 Y HSV-2, no existe una vacuna efectiva pero el aciclovir, famciclovir, valaciclovir y docosanol han demostrado ser efectivos. En el caso de HHV-3 sí existe una vacuna, al igual que son efectivos los análogos de nucleótidos. No hay un tratamiento efectivo para el virus de Epstein-Barr (HHV-4), pero el ganciclovir ha mostrado cierta eficacia cuando se usa en combinación con inductores del ciclo de replicación lítica del EBV (ácido valproico). Para citomegalovirus (HHV-5) y HHV-6, ganciclovir, valganciclovir y foscarnet son el tratamiento de elección; sin embargo, no existen regímenes de tratamiento aprobados para HHV-6 y HHV-7. ${ }^{2}$

No existen tratamientos antivirales formalmente aprobados para las neoplasias malignas asociadas al HHV-8. Las estrategias similares a las estudiadas para el EBV (foscarnet y ganciclovir) pueden ser útiles clínicamente. ${ }^{22}$ 
Es alentador que las infecciones por herpesvirus en el periodonto respondan a la terapia periodontal convencional (raspado y alisado radicular), a los tratamientos antisépticos y a la medicación sistémica antiviral. La terapia combinada con antibióticos (amoxicilina-metronidazol de 250 $\mathrm{mg} / 3$ veces al día durante 10 días) también ha demostrado resultados alentadores en combinación con la terapia antiviral y la terapia periodontal convencional. La disminución en el recuento de herpesvirus postratamiento se debe probablemente a una reducción de la inflamación gingival y, por lo tanto, una disminución en el número de virus en las células inflamatorias. Del mismo modo, los bajos recuentos de herpesvirus en sitios periodontales sanos pueden ser el resultado de una ausencia casi total de infección en células inflamatorias. En tanto que el virus no se detectó en la saliva de individuos periodontalmente sanos o en pacientes portadores de prótesis completas, se confirmaron los hallazgos de la estrecha relación entre el herpesvirus y la periodontitis. ${ }^{2}$

\section{Conclusión}

Es necesario investigar y prestar más atención al modelo "herpesvirus-bacteria» de la periodontitis, ya que su posible asociación proporciona una justificación para considerar nuevos enfoques para la prevención, diagnóstico y tratamiento de las enfermedades periodontales.

\section{AgradeCIMIEntos}

Agradecimientos especiales al D. en C. Miguel Padilla Rosas por su valiosa contribución del material fotográfico.

\section{Referencias}

1. Novak N, Peng WM. Dancing with the enemy: the interplay of herpes simplex virus with dendritic cells. British Society for Immunology. Clin Exp Immunol. 2005; 142 (3): 405-410.

2. Slots J, Slots H. Periodontal herpesvirus morbidity and treatment. Periodontol 2000. 2019; 79 (1): 210-220.

3. Crimi S, Fiorillo L, Bianch A, D’Amico C, Amoroso G, Gorassini $\mathrm{F}$ et al. Herpes virus, oral clinical signs and QoL: systematic review of recent data. Viruses. 2019; 11 (5): pii: E463.

4. Muzammil, Jayanthi D, Faizuddin M, Noor Ahamadi HM. Association of interferon lambda-1 with herpes simplex viruses-1 and -2, Epstein-Barr virus, and human cytomegalovirus in chronic periodontitis. J Investig Clin Dent. 2017; 8 (2).

5. Mohammad Mukhit Abdul Gaffar Kazi, Renu Bharadwaj. Role of herpesviruses in chronic periodontitis and their association with clinical parameters and in increasing severity of the disease. Eur J Dent. 2017; 11 (3): 299-304.

6. Zhu C, Li F, Wong MC, Feng XP, Lu HX, Xu W. Association between herpesviruses and chronic periodontitis: a metaanalysis based on case-control studies. PLoS One. 2015; 10 (12): e0144319.

7. Rodrigues PM, Teixeira AL, Kustner EC, Medeiros R. Are herpes virus associated to aggressive periodontitis? A review of literature. J Oral Maxillofac Pathol. 2015; 19 (3): 348-355.

8. Botero JE, Parra B, Jaramillo A, Contreras A. Subgingival human cytomegalovirus correlates with increased clinical periodontal parameters and bacterial coinfection in periodontitis. J Periodontol. 2007; 78 (12): 2303-2310.

9. Bascones-Martínez A, Pousa-Castro. Herpesvirus. Avances en Odontoestomatología. 2011; 27 (1): 11-24.

10. Slots J. Periodontitis: facts, fallacies and the future. Periodontology 2000. 2017; 75 (1): 7-23.

11. Dwyer DE, Cunningham AL. Herpes simplex and varicellazoster virus infections. Med J Aust. 2002; 177 (5): 267-273.

12. Beauman JG. Genital herpes: a review. Am Fam Physician. 2005; 72 (8): 1527-1534.

13. Cunningham AL, Breuer J, Dwyer DE, Gronow DW, Helme $\mathrm{RD}$, Litt JC. The prevention and management of herpes zoster. Med J Aust. 2008; 188 (3): 171-176.

14. Taylor MD. Cytomegalovirus. Am Fam Physician. 2003; 67 (3): 519-524.

15. Rafailidis PI, Mourtzoukou EG, Varbobitis IC, Falagas ME. Severe cytomegalovirus infection in apparently immunocompetent patients: a systematic review. Virol J. 2008; 5: 47.

16. Crawford DH. Biology and disease associations of EpsteinBarr virus. Philosophical Transactions of the Royal Society B. Biological Sciences. 2001; 356 (1408): 461-473.

17. De Lejarazu RO, Domínguez-Gil M, Jiménez S. Herpesvirus humano 8: implicaciones patógenas y diagnóstico. Control Calidad SEIMC. 2004; 1-13.

18. Hong YJ, Lim MS, Hwang SM, Kim TS, Park KU, Song J, Kim EC. Detection of herpes simplex and varicella-zoster virus in clinical specimens by multiplex real-time PCR and melting curve analysis. Biomed Res Int. 2014; 2014: 261947.

19. Gao Z, Lv J, Wang M. Epstein-Barr virus is associated with periodontal diseases. Medicine (Baltimore). 2017; 96 (6): 1-6.

20. Carballal G, Oubiña JR. Virus herpes simplex: herpesvirus humano (HHV) 1 y HHV-2. Virología Médica. 2015, pp. 396-400.

21. Brenner N, Mentzer AJ, Butt J, Michel A, Prager K, Brozy $\mathrm{J}$ et al. Validation of multiplex serology detecting human herpesviruses. PLoS One. 2018; 13 (12): e0209379.

22. Kornfeind EM, Visalli RJ. Human herpesvirus portal proteins: structure, function, and antiviral prospects. Rev Med Virol. 2018; 28 (3): e1972.

Correspondencia:

Cristian Gabriel Guerrero Bernal Departamento de Microbiología y Patología, Centro Universitario de Ciencias de la Salud, Universidad de Guadalajara. Tel: 1058-5200, ext.34242

E-mail: cristianggbernal@gmail.com 